\title{
Interactive English Reading Community Based on Social Network Sites
}

\author{
CHEN Min \\ China Youth University of Political Studies, Beijing, China
}

\begin{abstract}
One of the major trends in the reform of English language teaching is the application of network technologies. This paper discusses the application of social network sites in building an interactive English reading community under the guidance of the constructivist learning theory and its influence on the learners' English reading. This SNS-aided reading community puts the students as the center and the teacher the guide, embodying students' subjectivity, equality, and interactivity. The study shows that the interactive English reading community can motivate students to read, improve their reading skills, and thus develop a new SNS-aided English reading model for English learners.
\end{abstract}

Keywords: social network sites, reading models, interactive reading, motivation of reading

\section{Introduction}

The teaching objectives in China's Teaching Syllabus for English Majors have emphasized the importance of developing students' abilities to acquire knowledge, critical thinking, and creativity based on an excellent language command and enhancing their values as well as expanding ultural knowledge. As a main course for English majors, reading courses (both intensive and extensive) play an important role in developing students' English skills and their learning capacities and comprehensive qualities. Nevertheless, in conventional reading courses students learn from the lectures given by teachers in class. Neither can such a changeless teaching model motivates students to take initiatives to read after class nor cultivate their capabilities of independent reading and thinking. In addition, though the reading textbooks for English majors contain classic articles, the textbooks do not keep pace with the fresh topics and provide latest information for learners. Consequently, the reading textbooks often fail to arouse the learners' interest in reading, leading to their limited reading.

Another problem of English learners' for teachers to solve is the relatively low reading proficiency. For instance, the syllabus requires English sophomores to read 120-180 words per minute and correctly understand over $70 \%$ of the contents; they should read a moderately difficult article with around 1,000 words and grasp the main idea in five minutes. Nevertheless, by using the reading comprehension part of a TEM-4 (Test for English Majors Band 4) to test the reading skills of 47 sophomores who were admitted to our university in 2012, we found that only $19 \%$ of these students met the requirements mentioned above, with their average reading speed at 90 words per minute and comprehension accuracy rate at 57\%. The test demonstrates students' low reading speed and poor comprehension abilities, which can hardly meet our teaching objectives. One reason for their low

CHEN Min, lecturer, master, Department of English Language and Literature, China Youth University of Political Sciences. 
reading speed and poor comprehension is that they read little. Accordingly, the reforms of English reading teaching are now aimed at diversifying the current teaching models, encouraging English majors to read more and strengthening their reading skills.

\section{Social Network Sites and English Teaching}

Social Network Sites (SNSs) is defined as "Internet applications that provide communication and interactive services in various ways for online users bonded by social relations or with common interests” (LI, 2014, p. 30). As the Internet developed rapidly in the 21st century, SNSs have drawn increasing attention as a new communication means. 2014 Report on Social Network User Behaviors in China released by the China Internet Network Information Center (CNNIC) has shown that by the end of June, 2014, 61.7\% netizens have embarked on social network platforms, which are dominated by young people. The rapidly developed SNSs have fueled in new energy into social communications. Compared with traditional communication tools, SNSs have the following characteristics:

\section{Virtual Interpersonal Communications}

By simulating and rebuilding real interpersonal relations, social networks can help improve the speed and quality of interpersonal communications. Free from the limit of space and time, they are characterized by fast communications and extensive reaches, and can help learners with common interest organize group learning activities, stimulate and maintain their learning interest.

\section{Combination of Private and Public Space}

On SNSs, there are private spaces with focus on personal activities, and public places designed to support users' communications and interactions. As the two kinds of space are closely combined, users can communicate with each other via two models: "user-public space-user" and "user-user”. In this way, users have a variety of ways to visit others' private space and communicate with one or more users in public space, thus to find learning partners with common interest, while getting to know and interacting with others.

\section{User-Oriented Equal Interactions}

On SNSs, every user can collect, make, and spread content in a flat and equal structure, instead of in a top-down one. As thus, the interactions between users become the central activity in the social networks, which can help all the learners create and attend learning activities and interact with each other.

In recent years, an increasing number of domestic and foreign scholars carried our research on the applications of social network service in English learning. While some discussed SNS' role in English teaching targeting non-English majors (XIA, 2010; SHANG \& CHEN, 2013), others focused on application of SNS in facilitating English teaching and learning, especially collaborative learning, of English writing (ZHANG, 2013; CHEN \& CHEN, 2013). For example, ZHAI Rui discussed the advantages of the Weibo, a social network service and the possibility of its application in English teaching and learning. Another researcher, CHEN Mei-hua (2013) designed a Renren-based (a social media) an anonymous peer group review in English writing and found that it can help overcome the problems in peer review, such as single feedback source, face problem, social loafing, etc. Nevertheless, few carried out empirical research on the application of SNS in teaching of English reading. Therefore, it remains an urgent task for Chinese and overseas scholars to conduct feasibility study on the 
application of social networks SNS in English reading.

\section{Theoretical Basis-Theory of Constructivism}

In the 1990s, the constructivist learning theory was developed based on the cognitive school. Constructivist defined leaning as a process in which learners in a certain context actively construct knowledge by interacting with the outside environment and collaborate with others based upon their current knowledge and past experience. The teaching principles of constructivism are as follows:

Students should be the center of teaching and take the initiative to learn. Learning should not be deemed only as a process in which a teacher passes knowledge to students; instead, it is a process where students select, assembly, and process information according to their own needs and interests and cognitive knowledge.

The constructivists emphasize the importance of collaboration for meaning construction. Learning is not an isolated behavior of an individual learner but involves social construction. The interactions between a learner and the surrounding environment play an important role in the construction of knowledge. Organized and guided by their teacher, students discuss and communicate with each other and build learning groups and become a part of them.

The constructivists underscore the design of learning environment. Learning environment is a place where students can study, explore, and achieve their learning objectives by using various tools and information sources.

The interactions are regarded as an important means of meaning construction. The most valuable activity in teaching is encouraging students to form groups, where they communicate with each other and construct knowledge together. Such communications and construction serve as an important channel through which teachers and students communicate and exchange information.

To sum up, the teaching philosophy of constructivism is that students' enthusiasm, initiative, and creativity are crucial to education. Therefore, educators should create a learning environment where learners can take the initiative to study and build their knowledge (WU, 2006). Constructivism values collaborative learning, considering the cooperation and communication between students as a fundamental form and task of teaching. Based on the current situation of teaching of English reading and rapid development of the Internet aided English learning, we have attempted to explore how to enrich conventional teaching models through social network sites since September 2013, with the aim of encouraging English majors to read more and better by their own.

\section{Research Design}

(1) Research question

The research is attempted to answer the two questions:

Is it feasible to build a reading community based on SNS?

Does the SNS-aided reading model have the positive effect on the students reading?

(2) Research participants

The research participants are the two 2012 classes of China Youth University of Political Studies, majoring in English. In each class there are 50 subjects at the average age of 20, who are at the medium level of English learning. Everyone has a computer with access to the Internet and a smart mobile phone. Before they participate in the experiment, they had the knowledge and experience of using social network services. 
(3) Research tool

In order to observe the effects of social network sites on the reading of the subjects, we established English Reading Community on a social network site (reading.dajiashequ.com). This SNS is designed for different learning and working groups to share, collect files, pictures, and videos online. It also can provide one on one or multiple communication services. The subjects can upload the reading materials they recommend anytime, read the reading materials recommended by others, post the follow-up comments and read others' comments. The reading community provides both the private and public space. Therefore, it meets the requirements of the study.

(4) Research procedures

The research lasts one academic year, namely, two semesters. At the beginning of the first semester, we introduced the reading community to the subjects and demonstrated how to use it. The 50 subjects were divided into two groups based on their classes. Every week, two from each group selected and uploaded two reading materials of about 2,000 words for others to read, other subjects read them and posted their comments while the teacher monitored the whole activity. At the end of the research, the subjects completed a questionnaire designed to learn their feedback on the reading community. Fifty questionnaires were taken back and their feedback were analyzed.

(5) Data collection

The reading materials and follow-up comments can be saved automatically on the website, and therefore can be used to analyze their reading and communication. At the end of the research, data of the reading activity, including logging in, sharing materials and posts were collected from the background of the website.

\section{SNSs Aided Learning Models for English Reading-Interactive English Reading Community}

Guided by constructivism, an online interactive English reading community was established on a SNS (the dajiashequ.com), in an attempt to develop an SNS aided learning model for interactive English reading (see Figure 1).

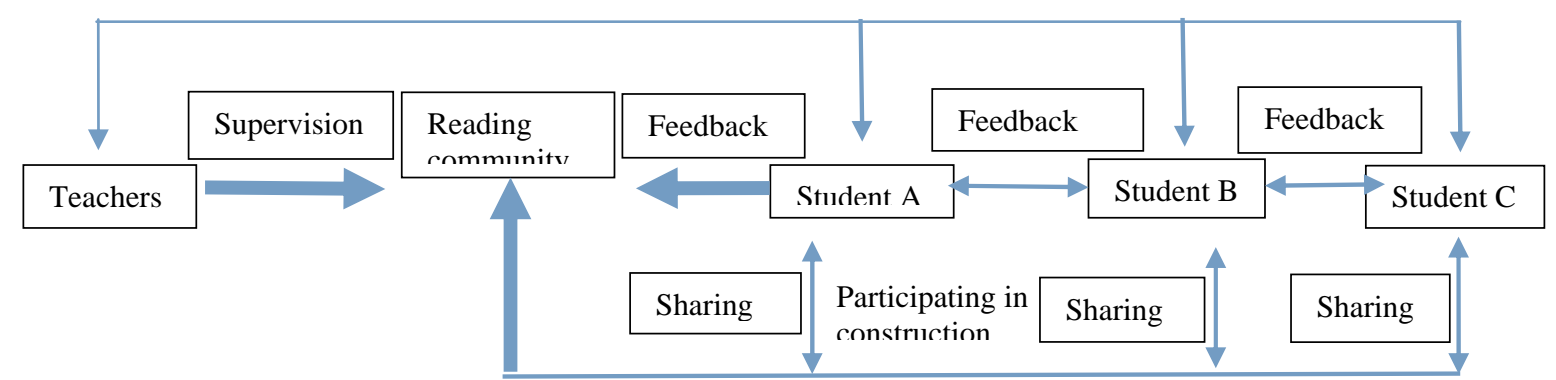

Figure 1. Model of interactive English reading community.

In this online interactive English reading community there are three key steps :"sharing”, "reading”, and “feedback”. Students can enter "My Center” after logging in a reading community. In "My Center”, students can upload reading materials they recommend either to all members, just one member, or to a specific reading group in the community so as to build the reading resources. Each material can be a news report, a short story, a piece of prose, or poems of around 1,000 words. In the "reading" step, students can enter "My Center" to read the latest shared materials, the comments made by other members on reading resources, and enter a specific group to read resources within. In the last step "feedback", students can save resources they are interested in after reading, and 
make comments on the materials uploaded by members in the community. Such remarks can be set either visible to all members or to just one of them. Students can also post comments on others' feedback and discuss with others their reading experience and express their ideas. Four features of an interactive reading community are demonstrated in the three steps:

\section{Emphasizing the Learners' Subjectivity in the Reading Activity and Thus Enable Them to Take Initiative}

The reading community is divided based on their classes, centers on learners and emphasizes both their input and output in learning. In a reading community, two students in a class post two recommended articles that they select online, with each containing no less than 1,000 words. In this way, students will become active knowledge explorer and constructor of learning resources, enhancing their critical reading ability by selecting reading resources.

\section{Underscoring Interactive and Collaborative Reading}

Due to the popularity of the Internet and mobile phones, the English reading community based on dajiashequ.com is free from the limit of time, space, and geography, thus enabling students to read on their computers and mobile phones at anytime and anywhere. In addition, the abundant online resources create an ideal environment for independent and interactive reading of learners. After reading an article, students can post follow-ups to make English comments, or express their views on related topics or others' opinions. As thus, interactive reading among students can be conducted, helping develop learners' independent critical thinking, while improving their writing and other English skills.

\section{Changing the Teachers' Roles from Knowledge Indoctrinators to Supervisors of the Reading Activity}

In this community, three teachers have different responsibilities, one responsible for screening reading materials for students by checking language quality, and the other two monitoring and giving feedback on online comments on reading materials. By either giving the thumbs-up to the students' remarks, or pointing out relevant problems, teachers have been turned from knowledge indoctrinators to supervisors and coordinators of online learning. In this way, students have gained the initiative to read and the quality of the reading can be guaranteed.

\section{Guaranteeing a Variety of Reading Materials are Offered in a Timely Manner}

As all members in the reading community recommend reading materials in turn, they are advised to select latest articles and news published by major foreign media. In this way, up-to-date materials can be continually offered, thus satisfying youths' psychological needs for new things and changes.

The data shows that after running for one year social reading in reading community keeps active. Every day, $24 \%$ of the subjects visit the website, with active rate four times that of popular social website Renren (6\% for renren.com). From September 2013 to June 2014, the subjects have shared 392 articles and posted 5,817 follow-ups. On average, on every article 15 subjects shared their views, indicating their enthusiasm for participating in reading activities and sharing their opinions.

In addition, a survey on the subjects has shown their positive attitudes towards social reading carried out on the social network site. Most respondents expressed strong support for reading activities via the dajiashequ.com, with $90 \%$ of them willing to exchange views in the reading community, $81 \%$ believing such community can facilitate communications between them, $83 \%$ finding discussions can help them have a better understanding of related articles, and $76 \%$ holding activities in the community have improved their skills. 
In the follow-up interview of the students using the reading community, we tried to understand their reading experiences and opinions about such platform. By analyzing the statistics, we have selected and interviewed four most active users and another four who seldom visited the reading community. One of the four active users said:

Thanks to the reading community, I was no longer a silent reader, as I often recommend some brilliant articles and interesting reports to other students to exchange our views. I feel fulfilled especially when others expressed their interest in the articles I recommended to them as well as their gains. (personal communication)

Another user: “It is quite rewarding to read other students' various comments, which reflect their different perspectives. Their comments have enabled me to see more than the article itself" (personal communication). The interview shows that social network sites can encourage students to participate in social reading activities, where they enjoyed sharing and turned from passive receivers to active creators of reading contents.

As to the less active users, one of them said :"I am not an enthusiastic reader, and the reading materials are either too difficult or too easy, making the reading a burden on me” (personal communication). Another student explained, he seldom read and he did not think it necessary to set up a specific online reading community as there were a wealth of reading materials on the Internet. As every student had their own preferences, he cannot decide which article can cater to them. These comments reveal that teachers need to take various measures to enhance the reading interest and skills of students who are less motivated and have encountered difficulty in sharing.

\section{Conclusion}

Guided by constructivism, an online interactive reading community for English majors has been designed to change monotonous teaching models, develop students' reading interest, improve their skills, and create a new way for learning reading. The interactive reading community has yielded satisfactory results after it ran for one year. Students are more motivated for reading and develop a regular time for reading. Nevertheless, more efforts are needed to improve the reading community. For example, more should be done to enhance the interactions between teachers and students and diversify the reading models, without changing the students' core roles and interactions between students in the community.

\section{References}

CHEN, M. H., \& CHEN, X. Y. (2013). A study on renren.com-based anonymous group review of English writing. Media in Foreign Language Teaching and Learning, 11, 104-105.

China Internet Network Information Center. (2014). Report on social network user behavior in China. Retrieved from http://www.cnnic.net.cn/hlwfzyj/hlwxzbg/sqbg/201408/t20140822_47860.htm

LI, X. T. (2014). Reflections on the construction of language learning SNS. China Educational Technology, 9, 29-32.

LI, Q. (2013). Teaching of college English writing: combination of cooperative writing and SNS platforms-an experiment on renren.com-based cooperative English writing. Journal of Shandong Radio and TV University, 3, 39-41.

SHANG, F. F., \& CHEN, Y. (2013), SNS platform applications to assisted college English teaching. Journal of Changchun Education Institute, 17, 77-78.

WU, X. Y. (2006). On the inspiring function of constructivism on English study. English Languages and Their Teaching, 2, 33-35.

XIA, J. (2010). SNS network english teaching based on six-dimension separation theory. Journal of Chongqing University of Science and Technology, 18, 193-195.

ZHAI, R. (2013). New strategy on teaching method of college reading course based on micro blog. Journal of Changsha Telecommunications and Technology Vocational College, 2, 124-127.

Zhang, J. (2013). An empiracal study of process writing for English majors in network Environment. Shandong Foreign Language Teaching Journal, 2, 68-73. 